\title{
Operating Performance of External Non-Involute Spur and Helical Gears: A Review
}

\author{
Ivan Okorn* - Marko Nagode - Jernej Klemenc \\ University of Ljubljana, Faculty of Mechanical Engineering, Ljubljana, Slovenia
}

In practical use, most gears have an involute shape of tooth flanks. However, external involute gears have some drawbacks, such as unfavourable kinematic conditions at the beginning and end of meshing, a limited minimum number of teeth, and the highly loaded convexconvex (i.e., non-conformal) contact. Researchers have developed and analysed various non-involute forms of tooth flanks, but they have not been widely accepted. The main reasons are higher manufacturing costs and sensitivity to manufacturing and assembly errors. Analyses of non-involute forms of teeth are mostly theoretical (analytical and numerical), while there is a lack of experimental confirmations of theoretical assumptions. This paper reviews external non-involute shapes, their operating characteristics and possibilities of use compared to involute gears. Established criteria, such as Hertzian pressure, oil film thickness, bending stress at the root of the tooth, contact temperature, and gear noise, were used for assessment. The results of analytical studies and experimental research on S-gears are presented in more detail. S-gears have a higher surface durability and a lower heat load when compared to involute gears. The usability of non-involute gears is increasing with the development of new technologies and materials. However, the advantages of non-involute shapes are not so significant that they could easily displace involute gears, which are cheaper to manufacture.

Keywords: non-involute gears, tooth profile, path of contact, Novikov gears, S-gears, gearing load capacity

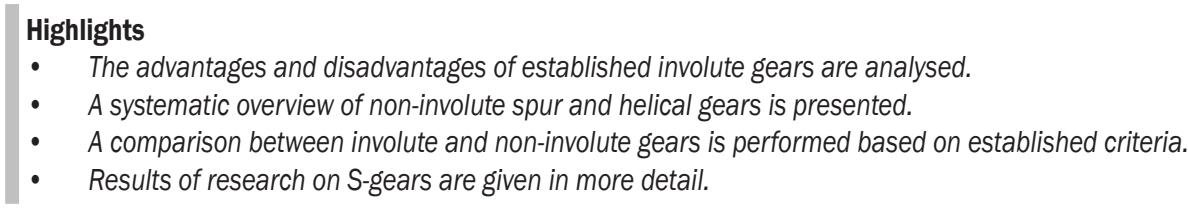

\section{INTRODUCTION}

To ensure smooth transmission of rotation between two gears, the flanks of the teeth must be designed to comply with the law of gearing: the common normal of the contacting flanks of teeth must pass through the pitch point $\mathrm{C}$ (Fig. 1b) at each point of contact. Involute gears with involute-shaped flanks of teeth are predominantly used in industry. Since non-involute gears will be compared with involute ones, the main properties of involute gears and definitions of the basic concepts will be summarised in Chapter 1. Our overview is limited to external gears. Involute gears are described in more detail in gear-books [1] to [3].

The principal disadvantages of external involute gears are:

- limited minimum number of pinion teeth,

- convex-convex contact of the tooth flanks and therefore a higher contact load than in the concave-convex contact, which occurs in most non-involute gears,

- unfavourable kinematic conditions (high sliding speed) at the beginning and end of meshing.

Many researchers have attempted to eliminate these disadvantages by changing the shape of the tooth profile. Non-involute gears can be designed so that the shape of the tooth flanks of the basic rack is defined first. The path of contact and the tooth flanks of pinion and wheel are defined using the known methods described in the literature [1]. In this way, the S-gears [4] and cosine gears [5] are defined. Another possibility is to define the shape of the tooth flanks based on a pre-selected path of contact. This procedure is used when defining a gearing with a parabolic path of contact [6].

In the follow-up, the theoretical criteria for assessing the load capacity of gears, their efficiency, and noise will be presented first. Next, an overview of non-involute tooth flanks and their comparison with involute teeth will be made. The results of theoretical analyses and tests from the cited literature will be given. The results of research on S-gears that were developed and tested at the Faculty of Mechanical Engineering, University of Ljubljana, will be presented in more detail [7] and [8]. The purpose of this paper is to give a systematic overview of noninvolute gears and their advantages and disadvantages. This reference-backed review is useful for both researchers of non-involute gears and for users in practical applications. The geometry and properties of individual non-involute forms are given in Chapter 3. A summary of properties of different non-involute 
gears compared to involute gears, areas of application and references are given in Tables 2 and 3 in Chapter 4.

\section{INVOLUTE GEARS}

In involute gears, the tooth flank profile has a shape of an involute, which is a curve drawn by a point on a line, which is rolled on the so-called base circle. The involute is mathematically defined by the involute function inv $\alpha$ (Fig. 1a). The curvature of the involute decreases when the radius of the base circle increases. If the radius of the basic circle is infinite, the involute is a straight line. The rack cutter for involute gears has a trapezoidal shape. Tools for manufacturing gears, therefore, have a simple straight-tooth shape, which is one of the most significant advantages of involute gears. The creation of the involute and the meshing of the teeth are shown in Fig. 1b, while the meshing of rack and pinion is shown in Fig. 2. The curve that connects the points of contact of the tooth flanks is called the path of contact. If the shape of the path of contact is defined, the shapes of the rack cutter profile and the flanks of teeth are also defined. In the case of involute gears, the path of contact is a line segment between the initial contact point $\mathrm{A}$ and the final contact point $\mathrm{E}$. The extension of the path of contact runs tangentially to the base circle of the gears. The angle between the direction of the normal force to the tooth flank and the direction of the tangent through the pitch point defines the pressure angle $\alpha$. In involute gearing, the direction of the force on the tooth does not change during meshing, which is favourable with regard to dynamic forces. Involute gears are not sensitive to centre distance errors. If the centre distance in the gearbox is greater than the theoretical one, the backlash increases, the pressure angle increases slightly, while kinematic conditions in the contact of the tooth flanks do not change significantly.

The operating properties of involute gears can be influenced by profile shift (Fig. 2). In a gear without a profile shift, the datum line of the rack runs tangentially to the pitch circle. The profile shift $V$ can be negative or positive displacement of the tooth profile with respect to the axis of rotation of the gear. An undercut appears in an involute gear with a small number of teeth. The undercut limit depends on the helix angle, pressure angle, and height of the flat part of the rack. In the case of spur gears with a pressure angle of $20^{\circ}$ and a rack as in Fig. 2, the undercut limit is at 17 teeth. To make a functional gear with a smaller number of teeth, a positive profile shift is needed. The choice of profile shifts is limited by the sharpness of teeth, so the number of teeth of an involute pinion has its lowest limit.

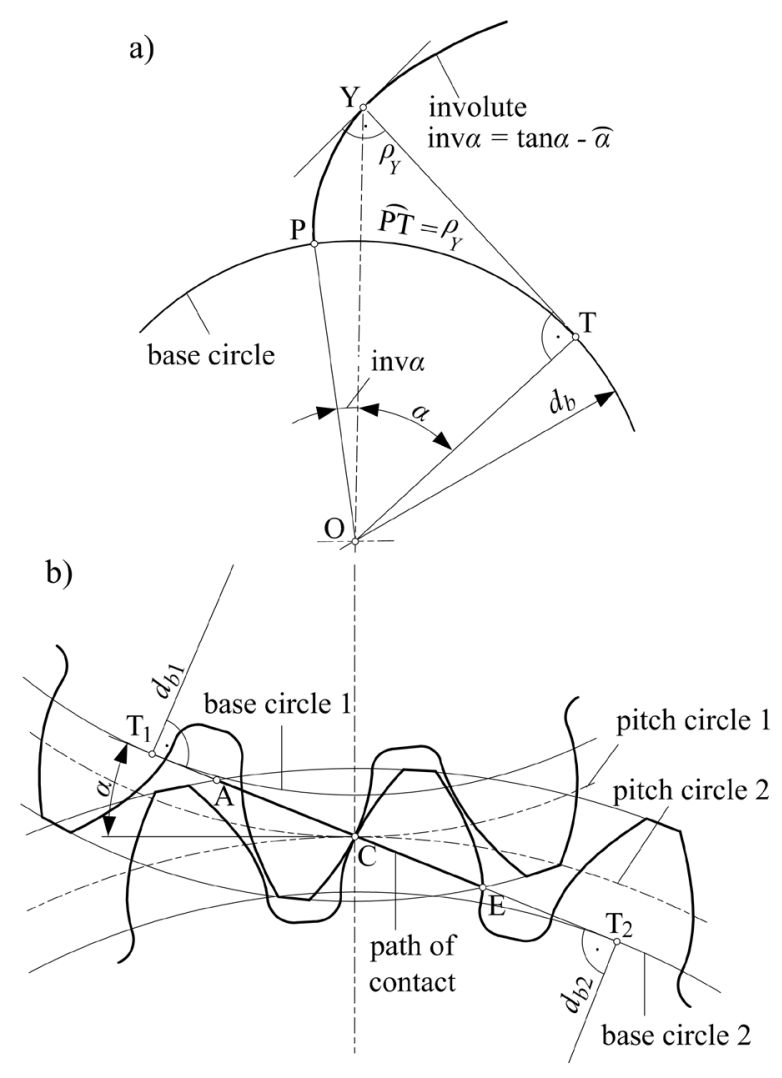

Fig. 1. Involute gears; a) the formation of an involute, and b) meshing of teeth

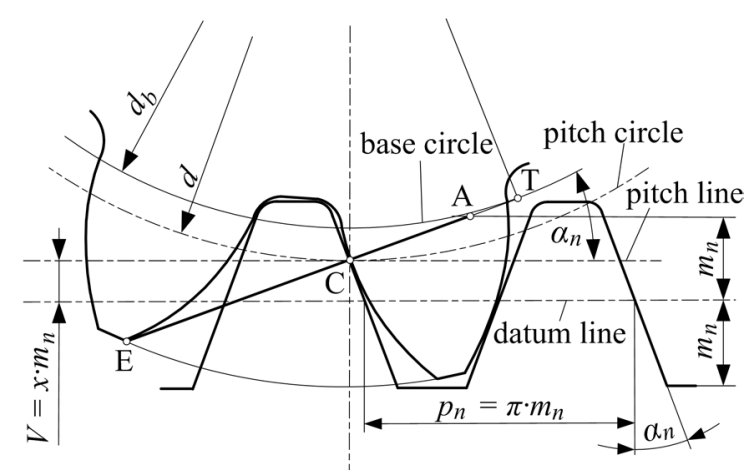

Fig. 2. Profile shift at involute gears

The sum of profile shifts is essential for the operating properties and the centre distance of the gear pair. When the sum of profile shifts is positive, the centre distance, pressure angle and the root load capacity of gears increase, while the contact ratio of gears decreases and the noise of gears increases [1] and [2]. The load capacity of involute gears can be increased, and noise and vibrations can be reduced by a tip relief profile modification [9] to [11] and crowning 
[12] to [14]. Special software (e.g., KISSsoft) enables the optimization of operating properties of involute gears.

A special design of involute gearing is asymmetric involute gearing. Its geometry and gear design are discussed by Kapelevich [15]. The gearing is not sensitive to centre-distance errors. The rack cutter is not symmetrical and not standardized. The pressure angle at the loading side is greater than on the unloading side, so the asymmetrical gearing has a higher tooth surface durability and higher root load capacity than the symmetrical gearing [16] to [18]. Sekar [19] discusses the friction between the tooth flanks as a function of geometric parameters and load. The author proves that power losses are smaller than with classical involute gears.

\section{CRITERIA FOR ASSESSING THE OPERATING PROPERTIES OF GEARS}

\subsection{Surface Durability of Gears}

During the expected lifespan of gears, there should be no tooth fractures or damages to the flanks of teeth. Flank damages include pitting, scuffing, micro pitting and abrasive wear [20]. Pitting is damage made due to fatigue of the tooth flank material. It starts with a crack that can be on the surface or underneath. Because of the cyclic load, the crack widens until a chip is formed, which is flushed out by the oil. Due to the pits formed on the surface of the flanks, the bearing surface of the flanks is reduced, and the contact load on the remaining surface increases. The criterion for the occurrence of pitting is the contact load, defined by the Hertz equation [2]. Evaluation of involute gears according to the ISO 6336-2 standard [21] is based on the following form of the Hertz equation:

$$
\sigma_{H}=\sqrt{\frac{F_{n}}{l_{d} \cdot \rho \cdot \pi \cdot\left(\frac{1-v_{1}^{2}}{E_{1}}+\frac{1-v_{2}^{2}}{E_{2}}\right)}} .
$$

At each point of contact, the line contact of teeth can be simulated with two cylinders with radii $\rho_{1}$ and $\rho_{2}$ or with a cylinder and a ring if one of the radii is negative and the contact is concave-convex. The relative radius of curvature is:

$$
\rho=\frac{\rho_{1} \cdot \rho_{2}}{\rho_{1}+\rho_{2}} .
$$

The Hertzian pressure between two cylindrical surfaces depends on the normal force $F_{n}$, material properties (modulus of elasticity $E$, Poisson number $v$ ), contact length $l_{d}$ and relative radius of curvature.
The relative radius of curvature depends on the shape of the tooth flanks. When designing non-involute gears, the trend is to achieve the largest possible relative radius of curvature, which consequently means a reduction of the Hertzian pressure. In the case of S-gears [4], the relative radius of curvature in the area at the beginning and end of meshing is significantly larger than in involute gears due to the concave-convex contact. However, in the vicinity of the pitch point $\mathrm{C}$, the convex-convex contact also exists in S-gears and, therefore, the relative radius of curvature is approximately the same as in involute gears. It depends on the pressure angle at point C. The same is true for cosine gears [5] and gears with a parabolic path of contact [6]. An analytical method for calculating the curvature radii for gears with a curved path of contact was developed in [7].

For the test conditions, materials, and geometry of the test gears, Hertzian pressures are defined at which pitting occurs after a certain number of tooth flank meshes. Values for involute gear materials are listed in the ISO 6336-5 standard [22]. When evaluating involute gears, the differences between the test conditions (lubricant, speed and the geometry of the test gears) and the actual conditions and geometry are considered by applying additional coefficients [21].

Due to the friction between the tooth flanks, the oil temperature increases, but the oil viscosity and the thickness of the oil film decrease. When the oil temperature exceeds the allowable value, the oil film breaks. When the protective layer is crushed, the two surfaces weld. Due to the sliding of the flanks, the joint collapses, and a gap is formed in the sliding direction. This type of damage is called "scuffing of gears". The evaluation of involute gears on scuffing is based on temperature criteria. Two methods are available in ISO/TS technical specification: the flash temperature method [23] and the integral temperature method [24]. The calculation of the flash temperature is based on Blok's formula [25] and [26].

$$
\begin{aligned}
\vartheta_{f l a}= & 0.62 \cdot \mu \cdot\left(w_{n}\right)^{0.75} \cdot\left(\frac{E^{\prime}}{\rho}\right)^{0.25} . \\
& \cdot \frac{\left|v_{t 1}-v_{t 2}\right|}{\left(\sqrt{B_{M 1} \cdot v_{t 1}}+\sqrt{B_{M 2} \cdot v_{t 2}}\right)} .
\end{aligned}
$$

Heat generation is influenced by the coefficient of friction $\mu$, load $\left(w_{n}=F_{n} / l_{d}\right)$, relative radius of curvature and sliding speed $v_{g}=v_{t 1}-v_{t 2}$. The denominator of the last term in Eq. (3) takes into account the heat dissipation from the contact. The substitute elasticity 
modulus $E^{\prime}$ depends on the elasticity modules of both gears and their Poisson numbers.

$$
\frac{1}{E^{\prime}}=\frac{1}{2} \cdot\left(\frac{1-v_{1}^{2}}{E_{1}}+\frac{1-v_{2}^{2}}{E_{2}}\right) .
$$

The frequently cited equation [1] and [27] is used for calculating the coefficient of friction.

$$
\mu=0.045 \cdot\left(\frac{w_{n}}{\left(v_{t 1}+v_{t 2}\right) \cdot \rho}\right)^{0.2} \cdot \eta_{0}^{-0.05} \cdot X_{R} .
$$

The coefficient of friction depends on load, relative radius of curvature, sum of tangential velocities $v_{t 1}+v_{t 2}$, viscosity of oil $\eta_{0}$ and surface roughness (taken into account by the $X_{R}$ coefficient). Non-involute gears with a curved path of contact, such as S-gears [4] and [7], cosine gears [5], and gears with a parabolic path of contact [6], have larger relative radii of curvature and lower sliding speeds at points that are critical for scuffing (at the beginning of meshing). The thermal load is lower at these points, so they are less susceptible to scuffing than involute gears are. Xue et al. [28] combined the dynamic load and transient thermal elastohydrodynamic lubrication (TEHL) to study the scuffing load capacity of spur gears. The hydrodynamic pressure, oil film thickness and flash temperature were calculated with a numerical method. The comparison between the TEHL and Blok's theory was implemented.

The minimum thickness of the oil film at the contact point is crucial for the occurrence of micropitting and abrasive wear of the tooth flanks. In general, the thickness of the oil film is calculated by solving the Reynolds differential equation. This procedure was used by $\mathrm{Xu}$ et al. [29] in the case of harmonic gear transmission. Typically, the DawsonHamrock equation [30] is used for the calculation of the minimum oil-film thickness. The general notation of the equation applies to the elliptical contact.

$$
\begin{aligned}
\frac{h_{0}}{\rho}= & 3.63 \cdot\left(\frac{v_{t 1}+v_{t 2}}{2} \cdot \frac{\eta_{0}}{E^{\prime} \cdot \rho}\right)^{0.68} \cdot\left(\alpha \cdot E^{\prime}\right)^{0.49} . \\
& \cdot\left(\frac{F_{n}}{E^{\prime} \cdot \rho}\right)^{-0.073} \cdot\left(1-0.61 e^{-0.68 \cdot k}\right) .
\end{aligned}
$$

Coeficient $k=a / b$ is the ellipticity parameter where $a$ and $b$ stand for ellipse axes. If the contact of the tooth flanks is a straight line, the expression in the last bracket of Eq. (6) is equal to 1. The equation can then be rearranged to the following form.

$$
\begin{array}{r}
h_{0}=\left(3.63 \cdot \eta_{0}^{0.68} \cdot \alpha^{0.49} \cdot E^{-0.117}\right) . \\
\cdot\left(\frac{v_{t 1}+v_{t 2}}{2}\right)^{0.68} \cdot \rho^{0.466} \cdot F_{n}^{-0.073} .
\end{array}
$$

Velocities, the relative radius of curvature, and load vary along the path of contact. Non-involute gears with a curved path of contact, such as S-gears [4] and [7], have a larger relative radius of curvature and a greater sum of tangential velocities at the beginning and end of meshing than the involute ones. The greater thickness of the oil film has a positive effect on both the damage of the flanks and the dynamic forces.

The evaluation of involute gears regarding micropitting is covered by the ISO/TS 6336-22 standard [31]. To assess the hazard of the micropitting, the relative thickness of the oil film is used, defined as:

$$
\lambda_{G F, F}=\frac{h_{y}}{0.5 \cdot\left(R_{a 1}+R_{a 2}\right)},
$$

where $h_{y}$ is the local film thickness on the assumption of smooth surfaces, while $R_{a 1}$ and $R_{a 2}$ are the arithmetic mean roughness values. Bergstedt et al. [32] have demonstrated experimentally that the probability of micropitting is lower on a smoother surface. Clarke et al. [33] and Liu et al. [34] provided an overview of the results of the latest micropitting research.

\subsection{Root Load Capacity of Gears}

The bending stress at the root of a tooth is an indication of load; the stress depends on the tooth thickness and the tooth fillet at the root. When evaluating involute gears for root load capacity, the bending stress at the root of the tooth is compared with the root fatigue strength, which is determined by gear tests. Analytical evaluation of involute gears is defined in the ISO 6336-3 standard [35]. Numerical methods are predominantly used to calculate the stress at the root of the teeth of non-involute gears, and the finite element method (FEM) is the prevailing numerical method. Analytical methods (such as beamlike models for cycloid gearings) are rare. Numerical analyses are used in many papers dealing with noninvolute gears [36] and [37].

\subsection{Power Losses and Gear Efficiency}

Friction between the flanks of teeth causes power losses. The friction power at the contact point $\mathrm{i}$ depends on the normal force $F_{n}$, the coefficient of friction $\mu$ and the sliding speed $v_{g}=v_{t 1}-v_{t 2}$.

$$
P_{f r i}=F_{n i} \cdot \mu_{i} \cdot\left|v_{t 1 i}-v_{t 2 i}\right| .
$$

In non-involute gears with a curved path of contact, such as S-gears [4] and [7], cosine gears [5], and gears with a parabolic path of contact [6], the 
sliding speeds are lower at the beginning and end of meshing; therefore, the power losses are also lower. The friction work during the meshing of one pair of teeth between the initial contact point $A$ and the final contact point $E$ is:

$$
W_{f r}=\sum_{i=1}^{n} P_{f r i} \cdot \Delta t_{i}=\int_{t_{A}}^{t_{E}} P_{f r} \cdot d t .
$$

With the known speed of the pinion $n_{1}$ in min $^{-1}$ and the number of teeth of the pinion $z_{1}$, the average friction power can be determined.

$$
\bar{P}_{f r}=\frac{z_{1} \cdot n_{1} \cdot W_{f r}}{60} .
$$

For involute gears, there is a theoretical method for determining power losses during the meshing of teeth. The procedure is described in the literature [1] and [2]. In the previous decade, an elastohydrodynamic lubrication (EHL) -based friction coefficient was developed and applied to the prediction of gear efficiency [38] and [39]. Ziegltrum et al. [40] compared the simulated load-dependent gear power losses of a transient thermal EHL model with the experimental results in the Forschungsstelle fur Zahnrader und Getriebebau (FZG) gear test rig. Results show a very strong correlation when taking into account the mixed lubrication.

\subsection{Vibration and Noise of Gears}

The main geometric parameter that affects gear noise is the contact ratio. Mesh stiffness depends on the contact ratio, and it has a decisive influence on vibration and noise level [28]. The gearing is more silent and quieter if the contact ratio is higher. For helical gears, the total contact ratio is the sum of the transverse contact ratio and the face contact ratio.

$$
\varepsilon=\varepsilon_{\alpha}+\varepsilon_{\beta} .
$$

The transverse contact ratio is the ratio between the arc length of action and the angular pitch.

$$
\varepsilon_{\alpha}=\frac{C_{1 A} C_{1 E}}{p_{n}}=\frac{C_{1 A} C_{1 E}}{m_{n} \cdot \pi} .
$$

For involute gears (with points of contact on a line), it is defined as the ratio between the length ACE and the base pitch (Fig. 1). The distance between the initial contact point $\mathrm{A}$ and the pitch point $\mathrm{C}$ is greater in involute gears, so their transverse contact ratio is higher. Non-involute gears with a curved path of contact, such as S-gears [4] and [7], cosine gears [5], and gears with a parabolic path of contact [6], have a shorter distance between the initial meshing point A and the pitch point $\mathrm{C}$, so the contact ratio is lower than that of involute gears. The contact ratio of involute gears can be changed by making a profile shift. If the sum of profile shifts is negative, the contact ratio is higher than if the sum is equal to 0 or positive. The overlap ratio is higher if a gear is wider and if the helix angle is larger.

The force on the tooth acts perpendicularly to the tooth flank profile. Because the path of contact is a straight line at involute gears, the direction of the force does not change during meshing, which has a good effect on vibrations. Vibration and noise of gears are decisively affected by tooth deviations [41]. The noise of involute and non-involute gears can only be adequately compared if the gears have been made in the same accuracy class. Greater manufacturing accuracy significantly reduces vibration and noise levels.

\section{NON-INVOLUTE GEARS}

Various forms of non-involute gears are presented in this chapter. Operating properties are described for each gear type, supported by theoretical and experimental research. A comparison with comparable involute gears is given.

\subsection{Cycloid Gearing}

The flank of the cycloid gear tooth consists of a hypo- and an epicycloid [3]. A cycloid is a curve produced by tracing a path of a chosen point on the circumference of a circle that rolls around a fixed base circle. The shape of the addendum flank of the tooth is obtained by rolling the circle on the outer side of the base circle, while the shape of the dedendum flank of the tooth is obtained by rolling a circle inside the base circle (Fig. 3). During meshing, the hypocycloid and the epicycloid touch, the touch is concave-convex, and the path of contact has a shape of circular arcs. The rack has flanks curved in the shape of an orthocycloid, which is obtained by rolling a circle along a straight line. The shape of the hypocycloid depends on the ratio of diameters of the rolling circle and the base circle $\left(k_{c}\right)$. The hypocycloid is a straight line if the value of $k_{c}=0.5$. The contact of the hypo- and the epicycloid is concave-convex when $k_{c}<0.5$, so the contact pressure is lower than that of involute gears. In these cases, the relative sliding is also lower than with comparable involute gears. The critical point of the gearing is the pitch point $\mathrm{C}$, where a transition from the epicycloid to the hypocycloid occurs. In the 
area of the pitch point, the relative curvature radii are very small, while the contact pressure is higher than in involute gears.

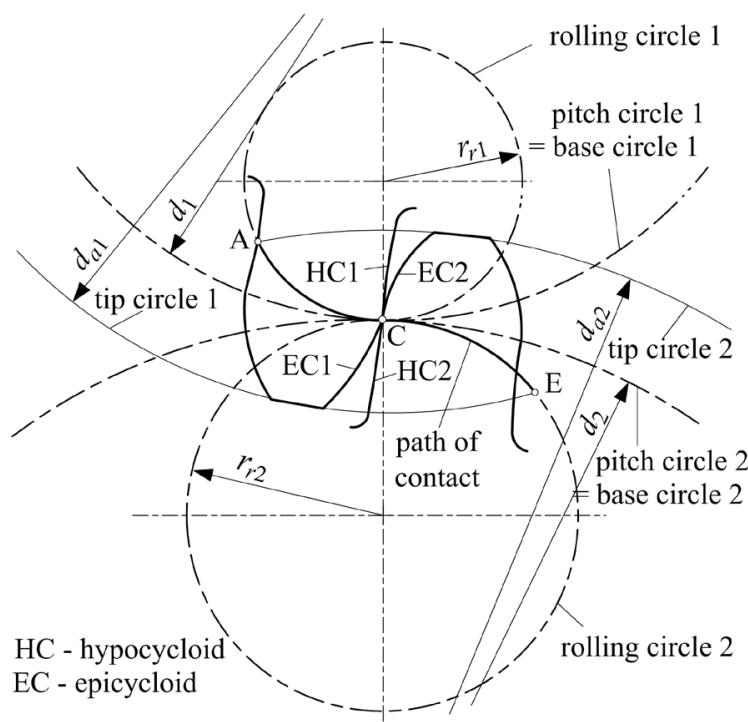

Fig. 3. Cycloid gears

A pinion can have a very small number of teeth (theoretically only two or three). Cycloid gears with two or three teeth are used for rotors in Roots blowers. Gearing is very sensitive to centre distance errors and does not allow a profile shift. If there is an error in the centre distance, vibrations increase. Manufacturing gears is a complicated and expensive process. This type of gears is used in precision mechanics (e.g., mechanical clocks).

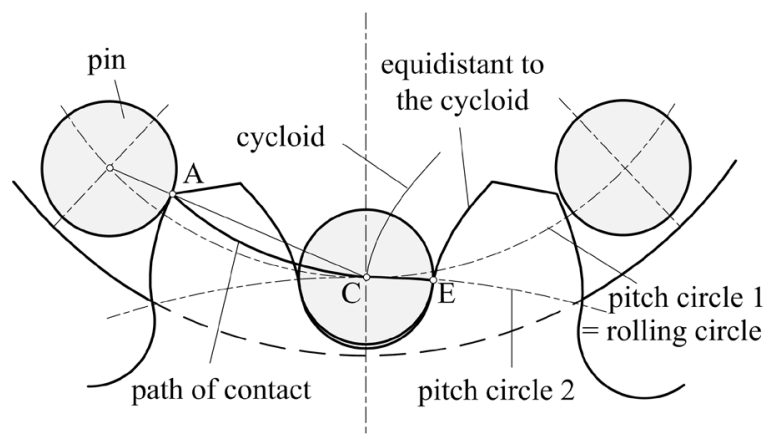

Fig. 4. Lantern gears

One special example of cycloid gearing is lantern gearing (Fig. 4) with pins on one of the gears. The flank of the gear tooth has the shape of an equidistant cycloid. The contact point on the pin slides along the flank of the gear tooth during meshing. The lantern gearing is only suitable for small circumferential speeds, e.g., drives with large driven gears in transport devices. A special shape of the cycloid gear is installed in the rotary vector cycloidal-pin drive [42], used in robots. The main feature of such a gearbox is a large gear ratio.

Peng et al. [43] developed a new form of cycloid gearing named arc-tooth-trace cycloid gear (Fig. 5).

a)

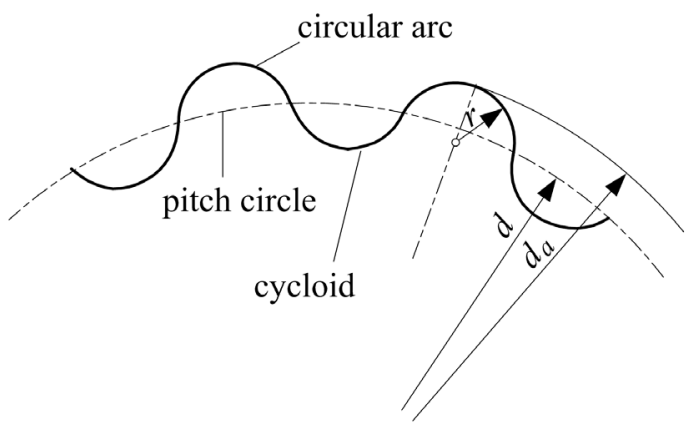

b)

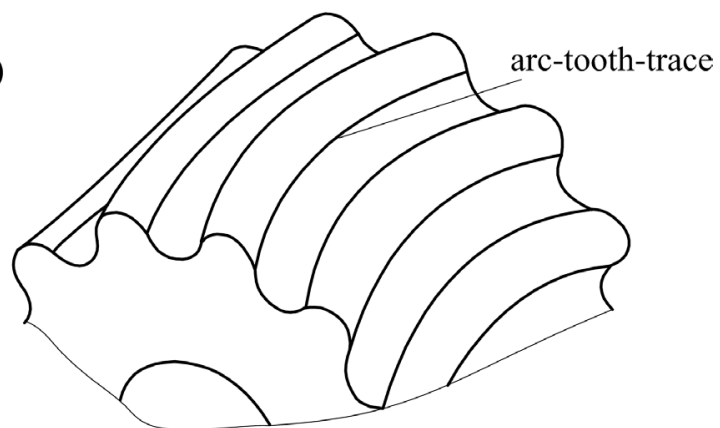

Fig. 5. Arc-tooth-trace cycloid gear; a) tooth profile, and b) arc-tooth-trace; adapted from [43]

The tooth trace of the gear is a segment of a circular arc. The profile of the tooth flank consists of two parts: above the reference circle is a circular arc segment, while a cycloid segment is below the circle. Equations for describing the geometry of the gearing and calculation of the contact ratio are derived in the paper. The transverse contact ratio is a constant value (0.5), while the overlap ratio depends on the module and the radius of a circular arc. 3D models of the new gears and comparable involute gears were made. The results of the numerical analysis show that the new gearing has $17 \%$ higher tooth surface durability and $35 \%$ higher root load capacity than involute gearing.

\subsection{Helical gears with circular arc teeth}

In 1926, Wildhaber [44] invented helical gearing with circular arc teeth (in a normal cross-section). Independently, a similar shape (a tooth profile with a circular arc in the front face) was invented 30 years later by Novikov [45]. Due to a similar shape, researchers in the past had named the gearing with the 
sides of teeth in the form of circular arcs as WildhaberNovikov gearing, or shorter W-N gearing. Radzevich [46] and [47] clarifies differences between the two systems and explains why Wildhaber and Novikov gearing should be addressed separately. In his opinion, the name "W-N gearing" is incorrect. The geometry of the original Novikov gearing is shown in Fig. 6 . This kind of gearing was applied in the final reduction stage of a Westland Lynx helicopter gearbox [48].

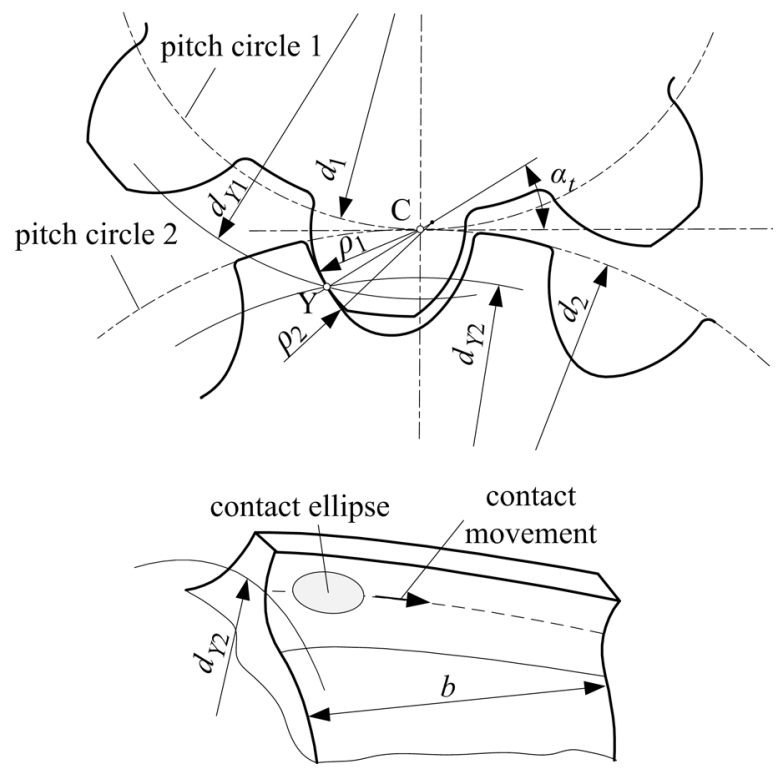

Fig. 6. Original Novikov gearing

The touch of the teeth is concave-convex. The contact surface has (in theory) an elliptical shape under load. When two gears rotate, the contact surface travels in the axial direction, parallel to the axis of the gear rotation. Transmission of rotation is continuous if the overlap ratio is higher than 1 . To ensure the lateral backlash, the radius of the pinion's circular arc must be slightly larger than the circular arc radius of the gear wheel.

Dyson et al. [49] and [50] discuss the gearing geometry and kinematics in detail and present design instructions. Contact stress during meshing was analysed in more detail by Coulbourne [51]. Due to the concave-convex contact, contact stress is lower than in involute gearing. According to Niemman's research [52], W-N gearing has 1.5 to 3 times higher surface durability than comparable involute gearing. These values apply to a gear shape when $\rho_{1}=\rho_{2}$. Differences decrease with an increasing helix angle. The influence of pressure angle and root fillet on the stress in the tooth root is discussed by Tsay [53]. His analysis was performed using FEM. Results of analyses indicate that the W-N gearing has a slightly lower root load capacity than the involute gearing. The conditions for the formation of the oil film are better than in involute gearing [54].

Over the previous decade, Markovski and Batsch [55] have conducted numerical and experimental research on Novikov gearing. They incorporated errors that occur during manufacturing and assembly into their mathematical model. On the basis of numerical contact analysis, they analysed the impact of errors on the wear of tooth flanks. It turned out that the contact surface is not a real ellipse as it was theoretically assumed. They developed a method for measuring and displaying the contact surface of Novikov gearing [56]. They performed fatigue tests on Novikov gears $\left(m_{n}=3 \mathrm{~mm}, z_{1}=30, z_{2}=47, b=30\right.$ $\mathrm{mm}$ ) and comparable involute gears [57]. With the same torque on the pinion, the Novikov gears lasted three times longer till the first signs of pitting. This confirms that the surface durability of the Novikov gearing is about three times higher than the durability of involute gearing. They also measured vibration amplitudes on the housing. They were approximately five times higher than in the involute ones. The main reasons for this are slightly worse manufacturing accuracy and a small contact ratio. Batsch extended the research of Novikov gears to bevel gears [58]. A mathematical model of meshing is derived. Contact stresses and maximum bending stresses in Novikov gears and comparable spiral bevel gears are calculated numerically. In Novikov gears, the contact area is larger, so the calculated contact stresses are lower by approximately $22 \%$. Root stresses are higher by $27 \%$ on the Novikov pinion.

Litvin et al. [59] developed a new shape of the W-N helical gearing. The rack cutter has a parabolic shape instead of a circular shape (Fig. 7). The contact ellipse is longer and narrower than in the basic Novikov gearing. Advantages of the new W-N gearing compared to the basic Novikov gearing are lower noise and vibration, lower sensitivity to manufacturing and assembly errors, the possibility of grinding the gears, lower contact pressure and lower bending stress. The advantages were proven by a simulation of meshing and by numerical calculations of contact stresses and bending stresses.

W-N gearing can also be made with two meshing zones (Fig. 8a) [60]. Compared to gearing with a single-zone meshing, this one has lower meshing stiffness. The jerks at the beginning of the meshing are smaller, and the distribution of force on the teeth is more favourable. A rack cutter with two circular arcs for manufacturing such gearing is shown in Fig. 8a. 
a)

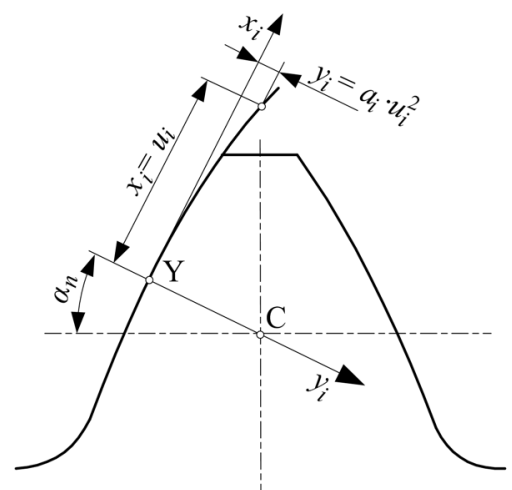

b)

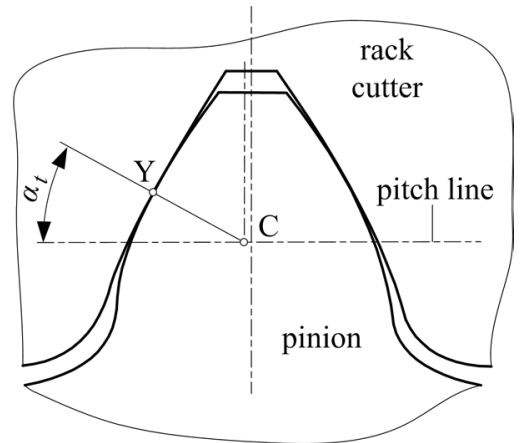

Fig. 7. New version of the W-N gear; a) rack-cutter in normal section, and b) transverse profiles; adapted from [59]

a)

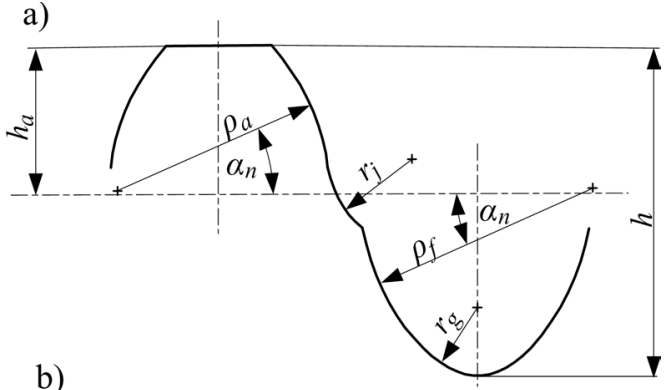

b)

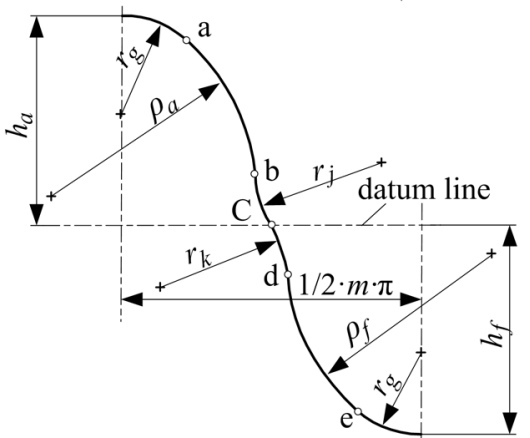

Fig. 8. Profiles of rack-cutter; a) W-N gears with two zones of meshing, and b) stepped triple circular-arc gears; adapted from [61]

The generated tooth flank has a singular point due to the sharp transition between the radii. To eliminate it, Yang [61] proposed a rack cutter with three circular arcs, shown in Fig. 8b. He named it a stepped triple circular-arc gearing. He developed a mathematical model of the gearing and performed a stress analysis using FEM.

Ariga and Nagata [62] also suggested an improvement of Wildhaber-Novikov gearing. The top of the new tooth profile has the shape of a circular arc, and the dedendum consists of two involutes. Tests have shown that these gears are less sensitive to centre-distance errors than conventional W-N gears.

The gearing with a gear profile composed of circular arcs was also developed by Hlebanja and Hlebanja [63] (Fig. 9), called uniform power transmission gears (UPTG). A theoretical comparison with involute gearing is made. To confirm its functionality, a model of aluminium gears was made.

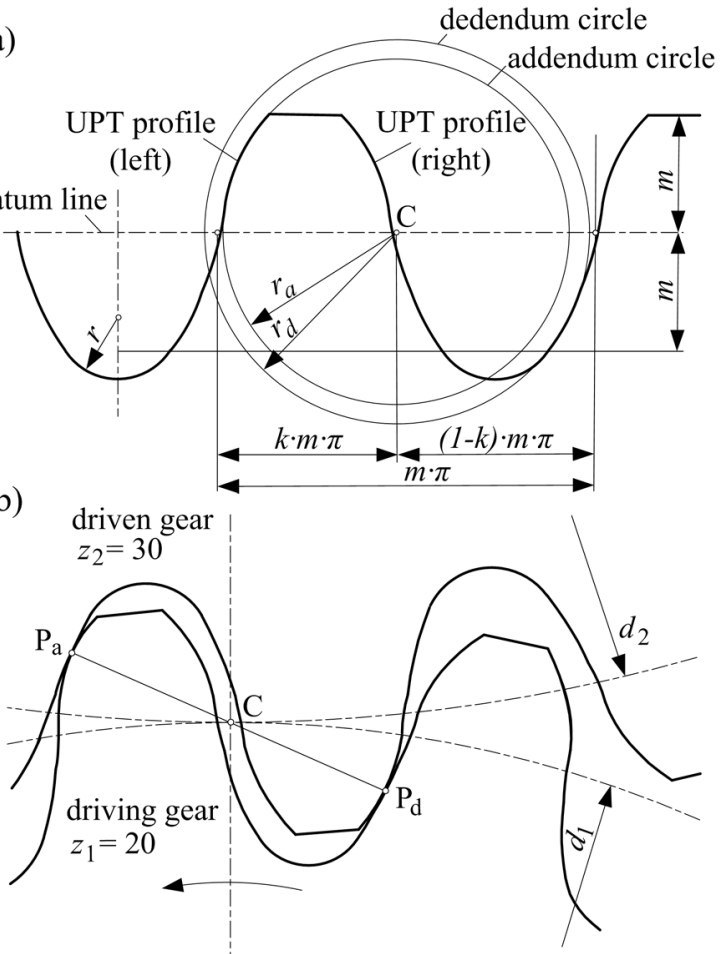

Fig. 9. UPT gears [63]; a) shape of the rack-cutter, and b) pair of UPT

Liang et al. [64] proposed gear transmission with a double circular arc-involute tooth profile. Three components are important in the generation of a tooth profile: the upper convex circular arc, the middle involute and the lower convex circular arc. Based on the equations of tooth surfaces, the software for calculating the data points of tooth surfaces was developed. The results were exported to the 3D drawing software. A numerical comparison of contact stresses and sliding coefficients between the involute 
gearing and the new gearing was made; both are lower in the new gearing. Proposed gears and involute gears were also compared experimentally. The transmission efficiency under different operating conditions is presented. The measured efficiency of the new gear was lower due to the lower manufacturing quality.

\subsection{Pure Rolling Helical Gears}

Chen et al. [65] developed novel circular arc helical gears (CAHGM) with pure rolling. Based on the meshing principle of space curve meshing, the parameter equations of the concave-convex circular arc profiles were established. A pair of CAHGM was manufactured via rapid prototyping technology. The contact ratio equation and the theoretical kinematic performance were validated. The gears have a large backlash which is harmful to the forward and reverse drives. Chen et al. [66] and [67] also developed pure rolling helical gears with convex-to-convex meshing type and pure rolling rack and pinion mechanism. Geometric design, meshing performance, and mechanical behaviour were presented. Parametric equations for contact curves and for the tooth surfaces were derived. A numerical comparison of contact stresses and bending stresses between the modified involute gearing and the new gearing was made. With new gearing, the maximum bending stresses are significantly lower, and the contact stresses are 1.5 to 2 times higher. The maximum contact stress can be decreased by increasing the tooth number and face width and decreasing the helix angle. Properties of pure rolling gearing have not yet been experimentally researched.

\subsection{Convoloid Gearing}

Berlinger and Coulbourne [68] developed a new type of gearing, named convoloid gearing. Its tooth's dedendum has a concave shape, while its addendum has a convex shape (Fig. 10). The transverse contact ratio is between 1.1 and 1.3 , while the overlap ratio is an integer. A theoretical and experimental comparison with equivalent involute gears is made. An important geometric parameter is the ratio between the width of the gear $b$ and centre distance $a$. If $b / a<0.2$, the convoloid gearing has no advantages. The load capacity ratio between convoloid and involute gears increases with increasing $b / a$ ratio. Test results show that $20 \%$ to $35 \%$ higher load capacity can be achieved with convoloid gears.

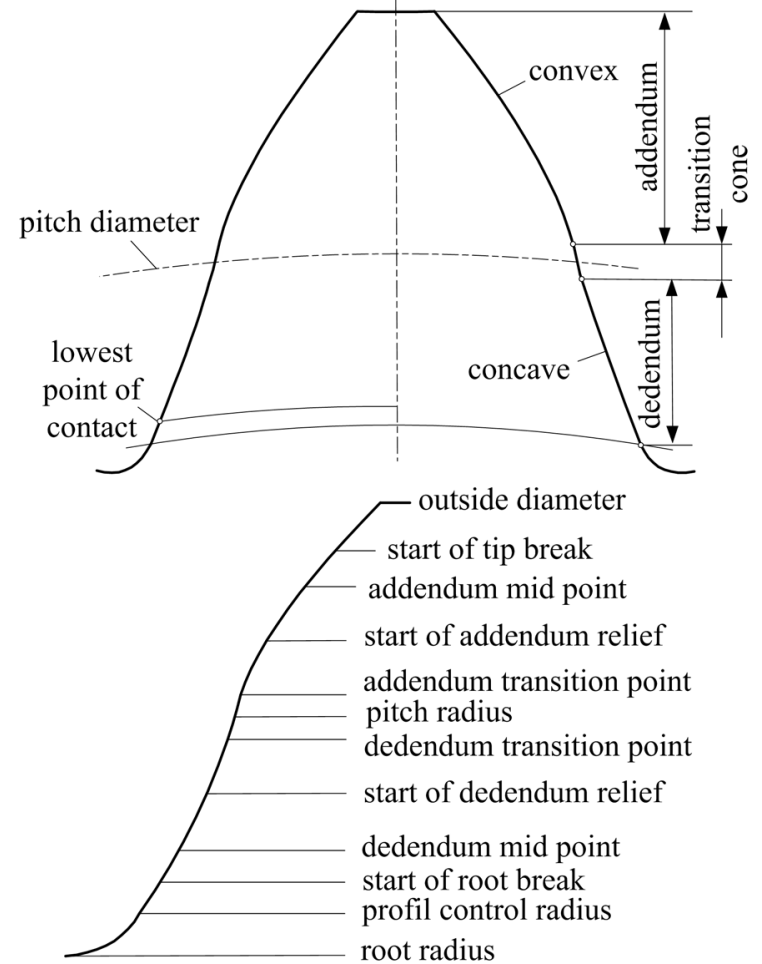

Fig. 10. Convoloid gearing; adapted from [68]

\subsection{Gears with Curved Paths of Contact}

\subsubsection{S-Gears}

Development of S-gears (invented by Hlebanja [69] and developed by Hlebanja et al. [70]) began in the 1970s. This type of gear was used in a rolling mill with a power of $1500 \mathrm{~kW}$ [71]. A path of contact in the shape of the letter $\mathrm{S}$ is a characteristic of this gearing. The first gearing had a small pressure angle at the pitch point C compared to today's shape. In the 1990s, the basic rack tooth profile equation was defined [72].

$$
y=a_{p} \cdot\left(1-(1-x)^{n}\right) .
$$

The following parameters were selected in [7]: $a_{p}=1.3$ and $n=1.9$. The shape of the tooth profile, the path of contact, and both tooth flanks are shown in Fig. 11. A tool for shaping S-gears with a module of $4.575 \mathrm{~mm}$ was made. Research studies of load capacity of spur S-gears made of steel and comparable involute spur gears were performed. Involute gears had a module $m_{n}=4.5 \mathrm{~mm}$, width $b=20 \mathrm{~mm}$, number of teeth $z_{1}=16$ and $z_{2}=24$, and the profile shift coefficients $x_{1}=0.233$ and $x_{2}=0.12$. Before the tests, the geometry of all gears was measured on a coordinate-measuring machine. S-gears were 
manufactured in accuracy classes 7 and 8 , and involute gears in class 6 (according to DIN 3962 [73]). The roughness of the tooth flanks was approximately the same in both types of gears.
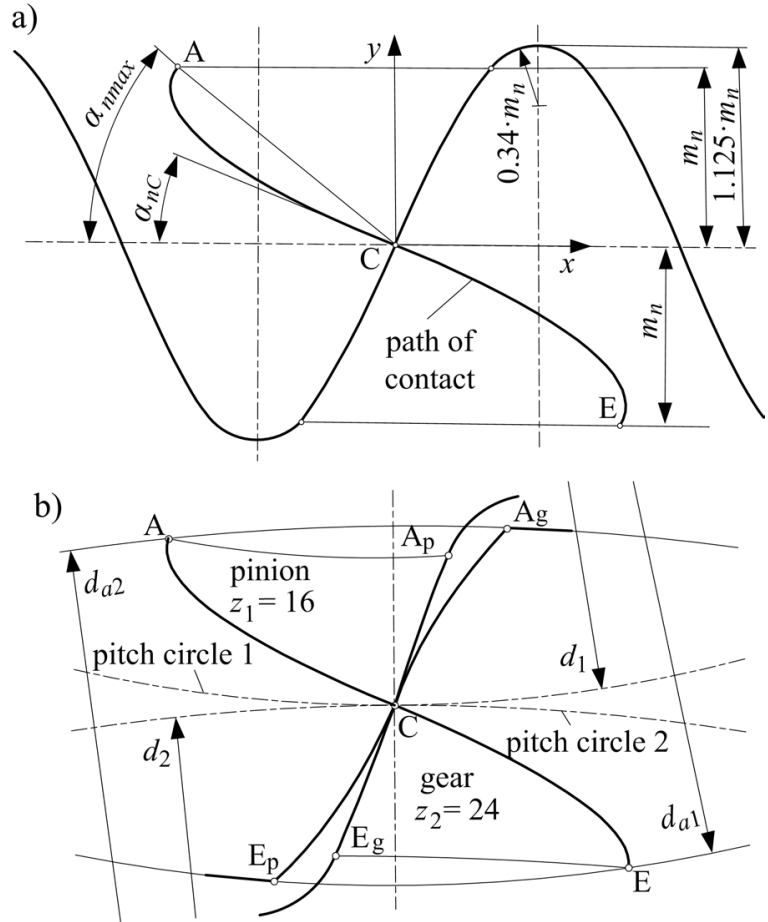

Fig. 11. S-gears [7]; a) basic rack tooth profile, and b) tooth flanks of S-gears

The load capacity tests were made on a standard FZG test rig [74] with a centre distance of $91.5 \mathrm{~mm}$. Theoretical calculations of Hertzian pressures, flash temperatures and oil film thicknesses were made for the geometry of the test gears and the test conditions. Figs. 12 and 13 show a comparison of Hertzian pressures and flash temperatures along the path of contact. Theories about the load capacity of S-gears were defined on the basis of the criteria described in Chapter 2.

The tests showed a significantly higher resistance of S-gears to scuffing, which is the expected result on the basis of the calculation of contact temperatures and oil film thickness at the beginning of meshing. In fatigue tests, pitting occurred in the pitch point area of S-gears, and in the dedendum of involute gears. S-gears withstood a slightly higher number of load cycles than involute ones (by approx. $20 \%$ ) [7] and [75]. The wear of S-gears was about one half lower during the same operating time due to a thicker oil film.
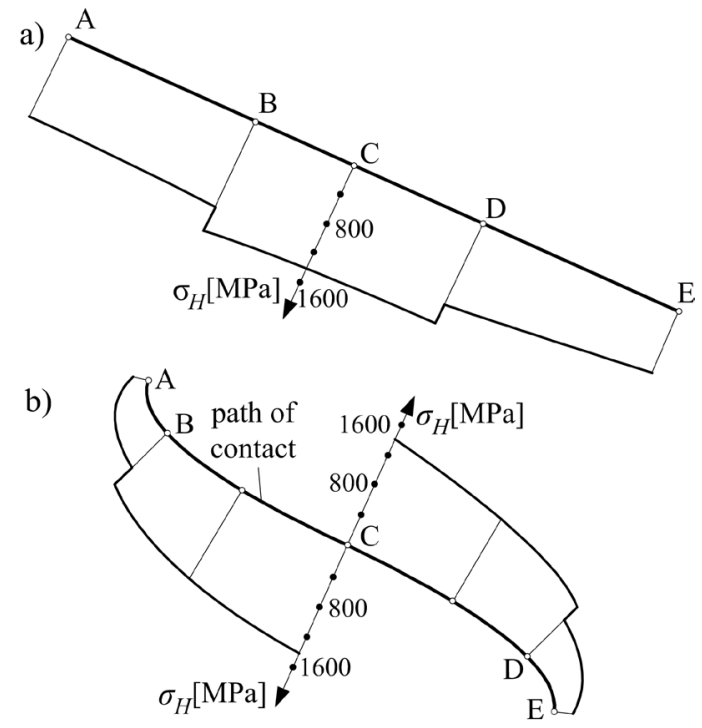

Fig. 12. Hertzian pressures during tests; a) involute gears, and b) S-Gears

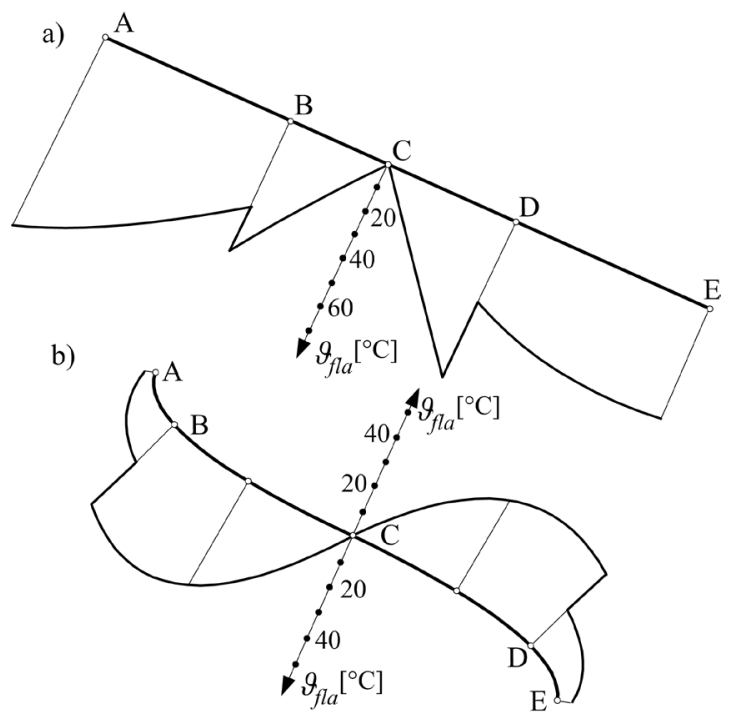

Fig. 13. Flash temperatures during tests; a) involute gears, and b) S-Gears

The heat load of the gears was estimated on the basis of oil temperature measurements [76] and [77]. S-gears with a modulus of $4.575 \mathrm{~mm}$ and involute gears with a modulus of $4.5 \mathrm{~mm}$, and the number of teeth of 16 and 24 were used in the tests. The oil temperature at the beginning of the test was $90{ }^{\circ} \mathrm{C}$. Oil temperatures after 15 minutes of operation at a given load in the standard FZG scuffing test are shown in Table 1. The measured temperatures prove that the heat load in S-gears is lower than in involute ones. 
Table 1. Oil temperature in ${ }^{\circ} \mathrm{C}$ at the end of the test at each load step

\begin{tabular}{lcccccc}
\hline Load step & 7 & 8 & 9 & 10 & 11 & 12 \\
\hline Torque $T_{1}[\mathrm{Nm}]$ & 183 & 239 & 302 & 372 & 450 & 543 \\
\hline S-gears & 94 & 97 & 102 & 106 & 113 & 118 \\
\hline Involute gears & 99 & 103 & 107 & 112 & 120 & 127 \\
\hline
\end{tabular}

One of the disadvantages of S-gears is a lower contact ratio than with involute gears. This weakness can be eliminated by using helical S-gears depicted in Fig. 14a. A gear pair with helical S-gears is shown in Fig. 14b. These gears were manufactured with the same shaping tool as the test spur S-gears. No experimental research on these gears has been made yet, but it is expected that operating characteristics will be better with helical gears than with spur S-gears.

a)

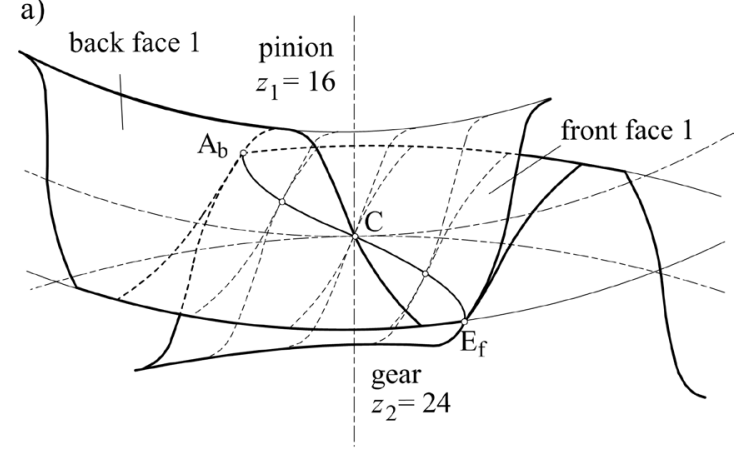

b)

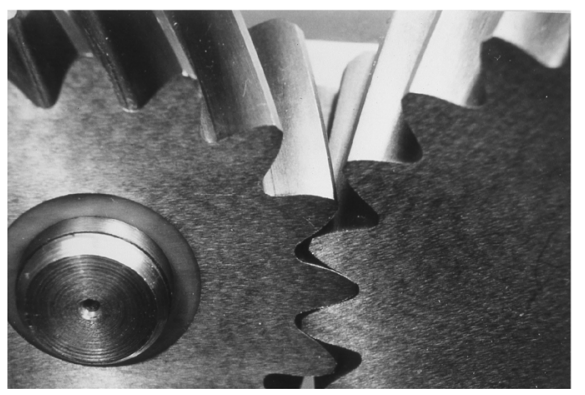

Fig. 14. Helical S-gears; a) contact of the teeth, and b) a gear pair

The S-gears can also be used in internal gears, which are widely used in planetary gears. The analysis of the load capacity of the internal S-gears is discussed by Hlebanja and Hlebanja [78]. Since the path of contact is a straight line in the pitch point region (which is similar to involute gears), the S-gears are significantly less sensitive to centre distance errors [79] than classic cycloid gearing. The operating properties of the S-gears depend on parameters $a_{p}$ and $n$. The influence of these parameters on the shape of teeth and operating properties is discussed by Kulovec and Duhovnik [80]. The S shape of the path of contact was also used in worm gears. Theoretical analysis of the situation and demonstration of the operation is given by Hlebanja et al. [81].

In the previous decade, the concept of using polymer S-gears has emerged. Polymer gears have a low modulus of elasticity, so the deformations are significantly higher. Most gears are made by injection moulding, with which it is not possible to achieve high precision. The contact temperature (which depends on the friction coefficient) has a significant impact on damage to polymer gears. The theoretical contact temperature of polymer S-gears is lower than that of involute gears with comparable geometry (same modulus and number of teeth), so the expected load-bearing capacity of S-gears is higher. In the first phase of research, the gears were made by injection moulding. The advantages of S-gears have not been demonstrated due to poor manufacturing accuracy and large deformations. In the second phase of research, the gears were made by hobbing. In this case, a higher load capacity of the S-gears was measured. Results on research concerning polymer S-gears were published in several papers [82] to [85]. A comparison of the efficiency of S-gears and involute gears was made. The results show better efficiency of S-gears [86]. Problems of polymeric S-gears are large deformations, small size of teeth (test gears had a module of $1 \mathrm{~mm}$ ) and manufacturing accuracy. The problem is general and specific to plastic S-gears. In steel gears, the deformations do not have such an effect on meshing. The accuracy class of the geometry is also higher for steel gears. Advantages of S-gears can be seen only if manufacturing accuracy is high enough, which can be achieved by hobbing. The question is, whether energy savings and higher load capacity justify the higher cost of manufacturing polymer S-gears.

\subsubsection{Cosine Gearing}

The shape of the flank of a pinion with a cosine gearing is described by a cosine function. Luo et al. [5] derived equations for the description of the tooth flank and the path of contact. A 3D model of the gearing was made, and a numerical analysis was performed with FEM. Contact ratio and sliding coefficient were calculated. Compared to involute gearing, the cosine gearing, which is discussed in [5], has the following characteristics: lower contact pressure (by approx. $22 \%$ ), lower root stress (by approx. $35 \%$ ), lower contact ratio (by $20 \%$ ) and considerably smaller sliding coefficient, both on gear and pinion. The stated properties of the gearing are valid generally, but the values in parentheses depend on the geometric 
parameters of the gears. Wadagaonkar and Shinde [87] confirmed lower contact stresses (by approx. $30 \%$ ) and lower bending stresses (by approx. $50 \%$ ) for their geometry of cosine gears.

\subsubsection{Gearing with a Parabolic Path of Contact}

Wang et al. [6] worked on gears with a parabolic path of contact. A mathematical model of the gearing was derived on the basis of a known path of contact. The influence of the parabola parameters on the shape of teeth of the pinion and the gear was analysed. The number of teeth in which dedendum undercut occurs is significantly smaller than in the case of involute gearing. A numerical comparison of contact stresses and bending stresses between the involute gearing and the new gearing was made; both are lower in the new gearing. This general statement is valid for any form of a parabola, while the quantitative values depend on the parabola parameters that can be optimized. Properties of a gearing with a parabolic path of contact have not yet been experimentally researched.

\subsubsection{Gears with a Constant Relative Radius of Curvature}

The relative radius of curvature has a decisive effect on the Hertzian contact pressure (Eq. (1)). Liu et al. [88] developed a new form of non-involute gearing based on a controlled relative radius of curvature. It was named constant relative curvature (CRC) gears. Equations were developed to calculate the profile of the rack cutter and gears. A mathematical model for the gearing was defined with a constant relative radius of curvature along the path of contact. The tooth profile is shown in Fig. 15. CRC and involute gears were compared analytically. The contact ratio was calculated for both types of gears; it was slightly lower for CRC gears. Contact stress, sliding coefficients, and oil film thicknesses were determined. The gearing has similar advantages over the involute gears as the

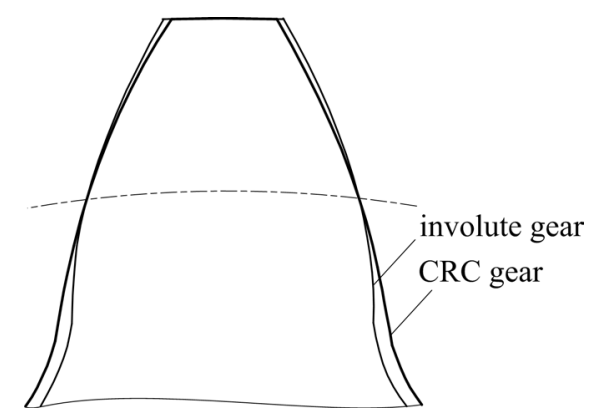

Fig. 15. Tooth profile of CRC gear and involute gear; adapted from [88]
S-gears: lower contact stress, thicker oil film and less sliding of flanks. The advantages of CRC gears have not yet been confirmed experimentally.

\section{DISCUSSION}

Gears in modern gearboxes must have the best possible efficiency, high load capacity, and low noise level combined with the smallest possible size. In recent decades, research has focused mainly on improving the properties of involute gears. The effects of geometry, lubrication, manufacturing accuracy and new materials on gearing load capacity and noise were researched in detail. New findings in tribology have significantly contributed to the improvement of the operational characteristics of involute gears.

Research on non-involute forms is, therefore, less frequent and less up-to-date. The development of software increased the possibilities of accurate analyses of non-involute forms. Mathematical models for defining geometry parameters have been developed to describe various non-involute shapes mentioned in this paper. A mathematical model of the gearing enables the creation of a $3 \mathrm{D}$ model of the gear pair, which can be analysed numerically. Analyses are relatively inexpensive and quickly feasible on modern computers. Most analyses are performed for the ideal shape of the tooth flanks. The accuracy of manufacturing and deformations of teeth significantly affect the shape of teeth and the operating characteristics. Involute and non-involute gears can only be compared if their manufacturing accuracy is comparable.

Based on the research of gears with a curved path of contact and the results of research on non-involute gears conducted and published by other authors, Table 2 assesses the properties of non-involute gears. The comparison refers to a comparable involute gear (the same number of teeth, helix angle, modulus, and accuracy class).

The three black dots in Table 2 indicate that the non-involute gearing is slightly better than the involute one in terms of the given property, while four and five dots indicate that it is significantly better than the involute one. At two black dots or less, the noninvolute gearing is worse than the involute one.

At the Faculty of Mechanical Engineering, University of Ljubljana, research was carried out on steel gears with a progressively curved path of contact [7]. Prototypes of S-gears and comparable involute gears were made. A theoretical comparison was performed according to the criteria described in Chapter 2. The theoretical assumptions were 


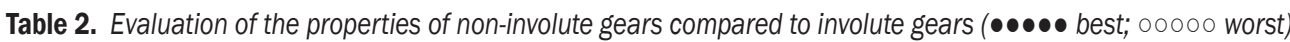

\begin{tabular}{|c|c|c|c|c|c|c|}
\hline & $\begin{array}{l}\text { Surface } \\
\text { durability }\end{array}$ & $\begin{array}{l}\text { Root load } \\
\text { capacity }\end{array}$ & $\begin{array}{l}\text { Gear efficiency, } \\
\text { Heat load }\end{array}$ & $\begin{array}{c}\text { Contact ratio, } \\
\text { Vibration and } \\
\text { noise }\end{array}$ & $\begin{array}{c}\text { Sensitivity to } \\
\text { manufacturing and } \\
\text { assembly errors }\end{array}$ & References \\
\hline Cycloid gears & $\bullet \bullet \bullet \circ \circ$ & $\bullet \bullet \bullet \circ \circ$ & $\bullet \bullet \bullet \circ \circ$ & $\bullet \bullet \circ \circ \circ$ & 00000 & [1], [3], [42] \\
\hline Lantern gears & $\bullet \bullet \circ \circ \circ$ & $\bullet \bullet \circ \circ 0$ & 00000 & $\bullet \bullet \circ \circ 0$ & $\bullet \circ 000$ & [1], [3] \\
\hline Arc-tooth-trace cycloid gears & $\bullet \bullet \bullet \circ \circ$ & $\bullet \bullet \bullet \circ \circ$ & $\bullet \bullet \bullet \circ \circ$ & $\bullet \bullet \circ \circ \circ$ & $\bullet \bullet \circ \circ 0$ & [43] \\
\hline Original Novikov gears & $\bullet \bullet \bullet \circ \circ$ & $\bullet \bullet \bullet \circ \circ$ & $\bullet \bullet \bullet \circ \circ$ & $\bullet \circ 000$ & 00000 & [44] to [58], [60] \\
\hline New W-N gears & $\bullet \bullet \bullet \bullet \circ$ & $\bullet \bullet \bullet \circ \circ$ & $\bullet \bullet \bullet \circ \circ$ & $\bullet \bullet \circ \circ \circ$ & $\bullet \bullet \circ \circ \circ$ & {$[36],[59],[62]$} \\
\hline Stepped triple circular-arc gears & $\bullet \bullet \bullet \circ \circ$ & $\bullet \bullet \bullet \circ \circ$ & $\bullet \bullet \bullet \circ \circ$ & $\bullet \bullet \circ \circ \circ$ & $\bullet \circ 000$ & {$[61]$} \\
\hline UPT Gears & $\bullet \bullet \bullet \circ \circ$ & $\bullet \bullet \bullet \circ \circ$ & $\bullet \bullet \bullet \circ \circ$ & $\bullet \bullet \circ \circ 0$ & $\bullet \bullet \circ \circ \circ$ & [63] \\
\hline Double circular arc-involute tooth profile & $\bullet \bullet \bullet \circ \circ$ & $\bullet \bullet \bullet \circ \circ$ & $\bullet \bullet \circ \circ \circ$ & $\bullet \bullet \circ \circ \circ$ & $\bullet \bullet \circ \circ \circ$ & {$[64]$} \\
\hline Pure rolling helical gears & $\bullet \bullet \bullet \circ \circ$ & $\bullet \bullet \bullet \circ \circ$ & $\bullet \bullet \bullet \bullet \bullet$ & $\bullet \bullet \circ \circ \circ$ & $\bullet \bullet \circ \circ \circ$ & {$[65],[66],[67]$} \\
\hline Convoloid gears & $\bullet \bullet \bullet \bullet \circ$ & $\bullet \bullet \bullet \circ \circ$ & $\bullet \bullet \bullet \circ \circ$ & $\bullet \bullet \circ \circ 0$ & $\bullet \bullet \circ \circ \circ$ & {$[68]$} \\
\hline S-Gears & $\bullet \bullet \bullet \bullet \circ$ & $\bullet \bullet \bullet \circ ०$ & $\bullet \bullet \bullet \bullet \circ$ & $\bullet \bullet ० 00$ & $\bullet \bullet \circ ० 0$ & $\begin{array}{c}{[4],[7],[8],[69] \text { to }} \\
{[72],[75] \text { to }[86]}\end{array}$ \\
\hline Cosine gears & $\bullet \bullet \bullet \circ \circ$ & $\bullet \bullet \bullet \circ ०$ & $\bullet \bullet \bullet \circ \circ$ & $\bullet \bullet \circ \circ 0$ & $\bullet \bullet \circ \circ 0$ & [5], [87] \\
\hline Gears with a parabolic path of contact & $\bullet \bullet \bullet \circ ০$ & $\bullet \bullet \bullet \circ \circ$ & $\bullet \bullet \bullet \circ \circ$ & $\bullet \bullet \circ \circ \circ$ & $\bullet 0000$ & {$[6]$} \\
\hline CRC-Gears & $\bullet \bullet \bullet \bullet ०$ & $\bullet \bullet \bullet \circ ०$ & $\bullet \bullet \bullet \circ \circ$ & $\bullet \bullet \circ \circ 0$ & $\bullet \bullet \circ \circ \circ$ & [88] \\
\hline
\end{tabular}

confirmed by tests at the FZG test rig. In the last decade, extensive research has also been conducted on plastic S-gears [8]. In papers on cosine gears [5], gears with a parabolic path of contact [6] and CRC gears [87], researchers listed similar properties as were found in S-gears.

Non-involute gears are relatively well researched analytically and numerically in terms of load capacity, while vibration and noise analyses remain lacking. We also lack experimental confirmations of theoretical assumptions regarding load capacity, efficiency, and noise.

Table 3. Areas of use of some non-involute gears

\begin{tabular}{|c|c|}
\hline & Areas of use \\
\hline $\begin{array}{l}\text { Cycloid gears } \\
\text { Cycloidal-pin drive }\end{array}$ & $\begin{array}{c}\text { watches, roots blowers, gear pumps } \\
\text { robots (large gear ratio) }\end{array}$ \\
\hline Lantern gears & $\begin{array}{c}\text { transport devices } \\
\text { (large gear ratio, small speeds) }\end{array}$ \\
\hline W-N gearing & $\begin{array}{l}\text { aircraft industry (helicopters), } \\
\text { oil industry }\end{array}$ \\
\hline Convoloid gearing & wind turbines \\
\hline S-Gears & $\begin{array}{l}\text { rolling mill, wind turbines, planetary } \\
\text { gearboxes, precision mechanics }\end{array}$ \\
\hline Cosine gearing & gear pumps \\
\hline $\begin{array}{l}\text { Gearing with a parabolic } \\
\text { path of contact }\end{array}$ & gear pumps \\
\hline
\end{tabular}

Areas of use of some non-involute gears are listed in Table 3. The gears presented in recent years are still in the research phase and have not yet been used in practical applications.

\section{CONCLUSIONS}

The paper presents both non-involute gears with a long history (cycloid gears, classical Novikov gears) and gears first presented in the last decade. New technologies (3D printing) enable easy and fast prototyping and testing of the functionality of new designs. Unfortunately, prototypes are not enough to convince users that new designs are useful.

Different gears with a curved path of contact, which show similar operating properties compared with involute gears (higher root load capacity and surface durability, lower tooth sliding and heat load, lower contact ratio), are discussed in more detail. Theoretical findings for spur S-gears have also been experimentally confirmed. Vibration and gear noise research is lacking. A higher contact ratio can be achieved with helical S-gears, and it would make sense to research them experimentally in the future.

Experimental studies on gears manufactured in real-life accuracy and surface roughness are rare. We believe that it is not possible to succeed in the market with a gearing that is not supported by experiments.

Therefore, the geometry and manufacturing of involute gears are much simpler and, above all, cheaper than that of non-involute gears. The evaluation of involute gears is carried out according to standards and recommendations. The references only list ISO standards and ISO technical specifications, but national standards (e.g., AGMA, DIN, etc.) and recommendations also exist (e.g., VDI). 
Because it is much more difficult to achieve the same accuracy with non-involute gears, they are still limited to specific applications. The current situation in development and research indicates that noninvolute gears cannot displace involute gears on a large scale.

\section{ACKNOWLEDGMENT}

The authors acknowledge the financial support from the Slovenian Research Agency (research core funding No. P2-0182).

\section{REFERENCES}

[1] Niemann, G., Winter, H. (2003). Maschinenelemente: Band 2. Springer Verlag, Berlin, Dol:10.1007/978-3-662-11873-3.

[2] Linke, H., Börner, J., Heß, R. (2016). Cylindrical gears: Calculation - Materials - Manufacturing. Carl Hanser Verlag, München, DOI:10.3139/9781569904909.

[3] Litvin, F.L., Fuentes, A. (2004). Gear Geometry and Applied Theory. Cambridge University Press, New York, D0l:10.1017/ CB09780511547126.

[4] Hlebanja, J., Okorn, I. (1999). Characteristische Eigenschaften von Zahnräder mit statig gekrümter Eingriffslinie. Antriebstechnick, vol. 38, no. 12, p. 55-58.

[5] Lou, S.M., Wu, Y., Wang, J. (2008). The generation principle and mathematical models of a novel cosine gear drive. Mechanism and Machine Theory, vol. 43, p. 1543-1556, D0I:10.1016/j.mechmachtheory.2007.12.007.

[6] Wang, J., Hou, L., Luo, S., Wu, R.Y. (2013). Active design of tooth profiles using parabolic curve as the line of action. Mechanism and Machine Theory, vol. 67, p. 47-63, DOI:10.1016/j.mechmachtheory.2013.04.002.

[7] Okorn, I. (2000). Research of Tooth Flank's Durability of Gears with Progressive Curved Path of Contact. PhD Thesis, University of Ljubljana, Ljubljana. (in Slovene)

[8] Zorko, D. (2019). Engineering Design of Polymer Gears with S Form of Teeth. PhD Thesis, University of Ljubljana, Ljubljana. (in Slovene)

[9] Wagaj, P., Kahraman, A. (2002). Influence of tooth profile modification on helical gear durability. Journal of Mechanical Design, vol. 124, no. 3, p. 501-510, Dol:10.1115/1.1485289.

[10] Sánchez, M.B., Pleguezuelos, M., Pedrero, J.I. (2019). Influence of profile modifications on meshing stiffness, load sharing and transmision error of involute spur gears. Mechanism and Machine Theory, vol. 139, p. 506-526, DOI:10.1016/j.mechmachtheory.2019.05.014.

[11] Wang, Z.G., Chen, Y.C. (2020). Design of helical gear set with adequate linear tip-relief leading to improved static and dynamic characteristics. Mechanism and Machine Theory, vol. 147, art. ID. 103742, D0l:10.1016/j. mechmachtheory.2019.103742.

[12] Bergseth, E., Björklund, S. (2010). Logarithmical crowning for spur gears. Strojniški vestnik - Journal of Mechanical Engineering, vol. 56, no. 4, p. 239-244.

[13] Wang, N., Li, X., Wang, K., Zeng, Q., Shen, X. (2017). A novel axial modification and simulation analysis of involute spur gear. Strojniški vestnik - Journal of Mechanical Engineering, vol. 63, no. 12, p. 736-745, D0l:10.5545/sv-jme.2017.4307.

[14] Weinberger, U., Otto, M., Stahl, K. (2020). Closed-form calculation of lead flank modification proposal for spur and helical gear stages. Journal of Mechanical Design, vol. 142, no. 3, art. ID. 031106, D0l:10.1115/1.4045396.

[15] Kapelevich, A.L. (2000). Geometry and design of involute spur gears with asymmetric teeth. Mechanism and Machine Theory, vol. 35, no. 1, p. 117-130, D0l:10.1016/S0094114X(99)00002-6.

[16] Mo, S., Ma, S., Jin, G. (2019). Research on composite bending stress of asymmetric gear in consideration of friction. Proceedings of the Institution of Mechanical Engineers, Part C: Journal of Mechanical Engineering Science, vol. 233, no. 8, p. 2939-2959, DOl:10.1177/0954406218797975.

[17] Mo, S., Ma, S., Jin, G. (2019). Design principle and modeling method of asymmetric involute internal helical gears. Proceedings of the Institution of Mechanical Engineers, Part C: Journal of Mechanical Engineering Science, vol. 233, no. 1, p. 244-255, DOI:10.1177/0954406218756443.

[18] Marimuthu, P., Muthuveerappan, G. (2016). Design of asymmetric normal contact ratio spur gear drive through direct design to enhance the load carrying capacity. Mechanism and Machine Theory, vol. 95, p. 22-34, Dol:10.1016/j. mechmachtheory.2015.08.013.

[19] Sekar, R.P. (2019). Determination of load dependent loss factor on asymmetric spur gear. Mechanism and Machine Theory, vol. 135, p. 322-335, D0l:10.1016/j. mechmachtheory.2019.02.011.

[20] Snidle, R.W., Evans, H.P. (2009). Some aspects of gear tribology. Proceedings IMechE, Part C: Journal of Mechanical Engineering Science, vol. 223, no. 1, p. 103-141, DOI:10.1243/09544062JMES1168.

[21] ISO 6336-2:2019. Calculation of load capacity of spur and helical gears - Part 2: Calculation of surface durability (pitting). International Organization for Standardization, Geneva.

[22] ISO 6336-5:2016. Calculation of load capacity of spur and helical gears - Part 5: Strength and quality of materials. International Organization for Standardization. Geneva.

[23] ISO/TS 6336-20:2017. Calculation of load capacity of spur and helical gears - Part 20: Calculation of scuffing load capacity (also applicable to bevel and hypoid gears) Flash temperature method. International Organization for Standardization. Geneva.

[24] ISO/TS 6336-21:2017. Calculation of load capacity of spur and helical gears - Part 21: Calculation of scuffing load capacity (also applicable to bevel and hypoid gears) Integral temperature method. International Organization for Standardization. Geneva.

[25] Blok, H. (1963). The flash temperature concept. Wear, vol. 6, no. 6 p. 483-494, Dol:10.1016/0043-1648(63)90283-7.

[26] Theyse, F.H. (1967). Die Blitztemperaturhypotese nach Blok und ihre praktische Anwenung bei Zahnräder. Schmierungstechnick, vol. 14, p. 22-29.

[27] Yu, L., Wang, G., Zou, S. (2017). The calculation of meshing efficiency of a new type of conical involute gear. Strojniški vestnik - Journal of Mechanical Engineering, vol. 63, no. 5, p. 320-330, D0I:10.5545/sv-jme.2016.3843. 
[28] Xue, J., Li, W., Qin, C. (2014). The scuffing load capacity of involute spur gear systems based on dynamic loads and transient thermal elastohydrodynamic lubrication. Tribology International, vol. 79, p. 74,83, D0l:10.1016/j. triboint.2014.05.024.

[29] Xu, X., Fan, X., Wei, P., Yang, B. (2020). Research on the lubrication characteristics of harmonic gear transmission meshing areas. Strojniški vestnik - Journal of Mechanical Engineering, vol. 66, no. 9, p. 513-522, Dol:10.5545/svjme.2020.6667.

[30] Dowson, D., Higginson, G.R. (1977). Elastohydrodinamic Lubrication. Pergamon Press, Oxford.

[31] ISO/TS 6336-22:2018. Calculation of load capacity of spur and helical gears - Part 22: Calculation of micropitting load capacity. International Organization for Standardization. Geneva.

[32] Bergstedt, E., Lin, J., Olofssen, U. (2020). Influence of gear surface roughness on the pitting and micropitting life. Proceedings of the Institution of Mechanical Engineers, , Part C: Journal of Mechanical Engineering Science, vol. 234, no. 24, p. 4953-4961, D0I:10.1177/0954406220931541.

[33] Clarke, A., Evans, H.P., Snidle, R.W. (2015). Understanding micropitting in gears. Proceedings of the Institution of Mechanical Engineers, Part C: Journal of Mechanical Engineering Science, vol. 230, no. 7-8, p. 1276-1289, DOl:10.1177/0954406215606934.

[34] Liu, H., Liu, H., Zhu, C., Zhou, Y. (2019). A review on micropitting studies of steel gears. Coatings, vol. 9, no. 1, art. ID 42, Dol:10.3390/coatings9010042.

[35] ISO 6336-3:2019. Calculation of load capacity of spur and helical gears - Part 3: Calculation of tooth bending strength. International Organization for Standardization. Geneva.

[36] Litvin, F.L., Fuentes, A., Gonzalez-Perez, A.l., Carnevali, L., Sep, T.M. (2000). New version of Novikov-Wildhaber helical gears: computerised design, simulation of meshing and stress analysis. Computer Methods in Applied Mechanics and Engineering, vol. 191, no. 49-50, p. 5707-5740, D0l:10.1016/ S0045-7825(02)00482-6.

[37] Zorko, D., Tavčar, J., Duhovnik, J. (2018). The influence of the tooth profile shape on the stress-strain in the gear. International Journal for Science, Technics and Innovations for the Industry: Machines, Tecnologies, Materials, vol. 12, no. 4, p. 153-156.

[38] Li, S. (2015). A thermal tribo-dynamic mechanical power loss model for spur gear pairs. Tribology International, vol. 88, p. 170-178, D0I:10.1016/j.triboint.2015.03.022.

[39] Liu, M., Xu, P., Zhang, J., Ding, H. (2019). Analysis of mechanical power loss of a helical gear pair based on the starved thermalelastohydrodynamic lubrication model. Industrial Lubrication and Tribology, vol. 72, no. 3, p. 333340, D0I:10.1108/ILT-06-2019-0225.

[40] Zigeltrum, A., Lohner, T., Stahl, K. (2017). TEHL simulation on the influence of lubricants on load-dependent gear losses. Tribology International, vol. 113, p. 252-261, D0l:10.1016/j. triboint.2016.12.018.

[41] Shuai, M., Shuai, M., Guoguang, J., Xiang, Y.Z. (2019). Research on dynamic load-sharing characteristics of two-stage asymmetric star gear system. IEEE Access, vol. 7, no. 1, p. 126799-126811, DOI:10.1109/ACCESS.2019.2937940.

[42] Li, T., Xu, H., Tian, M. (2020). A loaded analysis method for RV cycloidal-pin transmission based on the minimum energy principle. Strojniški vestnik - Journal of Mechanical Engineering, vol. 66, no. 11, p. 655-667, D0l:10.5545/svjme.2020.6868.

[43] Peng, Y., Song, A., Shan, Y., Lin, X. (2017). A novel arctooth-trace cycloid cylindrical gear. Mechanism and Machine Theory, vol. 118, p. 180-193, D0l:10.1016/j. mechmachtheory.2017.08.009.

[44] Wildhaber, E. (1926). Helical gearing, Patent 1601750. United States Patent and Trademark Office, Washington.

[45] Novikov, M.L. (1956). USSR Patent 109750, USSR, Moscow.

[46] Radzevich, S.P. (2020). High-conformal Gearing: Kinematics and Geometry. Elsevier, Amsterdam.

[47] Radzevich, S.P. (2018). An examination of high-conformal gearing. Gear Solutions, p. 31-39.

[48] Shotter, B.A. (1978). The Lynx transmission and conformal gearing. SAE Technical Paper, art ID 781041, DOl:10.4271/781041.

[49] Dyson, A., Evans, H., Snidle, R. (1986). Wildhaber-Novikov circular arc gears: Geometry and kinematics. Proceedings of the Royal Society of London. Series A, Mathematical and Physical Sciences, vol. 403, no. 1825, p. 313-340, DOI:10.1098/rspa.1986.0014.

[50] Dyson, A., Evans, H., Snidle, R. (1989). Wildhaber-Novikov circular arc gears: Some properties of relevance to their design. Proceedings of the Royal Society of London. Series A, Mathematical and Physical Sciences, vol. 425, no. 1869, p. 341-363, D0I:10.1098/rspa.1989.0110.

[51] Coulbourne, J.R. (1989). The contact stresses in Novikov gears. Mechanism and Machine Theory, vol. 24, no. 3, p. 223229, Dol:10.1016/0094-114X(89)90061-X.

[52] Niemann, G. (1961). Novikov gear system and other special gear systems for high load carrying capacity. VDI-Berichte, 47, p. 5-12.

[53] Tsay, C.-B., Wong, Z.H., Tao, S. (1989). The mathematical model of Wildhaber-Novikov gears applicable to finite element stress analysis. Mathematical and Computer Modelling, vol. 12, no. 8 p. 939-946, D0l:10.1016/0895-7177(89)90199-4.

[54] Evans, H.P., Snidle, R.W. (1993). Wildhaber-Novikov circular arc gears: Elastohydrodinamics. Journal of Tribology, vol. 115, no. 3, p. 487-492, D0l:10.1115/1.2921664.

[55] Markowski, T., Batsch, M. (2015). Tooth contact analysis of Novikov convexo-concave gears. Advances in Manufacturing Science and Technology, vol. 39, no. 1, p. 53-69, D0l:10.2478/ amst-2015-0004.

[56] Batsch, M., Markowski, T., Legutko, S., and Krolczyk, G.M. (2018). Measurement and mathematical model of convexoconcave Novikov gear mesh. Measurement, vol. 125, p. 516525, D0I:10.1016/j.measurement.2018.04.095.

[57] Batsch, M. (2016). Comparative fatigue testing of gears with involute and convexo-concave teeth profiles. Advances in Manufacturing Science and Technology, vol. 40, no. 2, p. 5-25, D0I:10.2478/amst-2016-0007.

[58] Batsch, M. (2020). Mathematical model and tooth contact analysis of convexo-concave helical bevel Novikov gear mesh. 
Mechanism and Machine Theory, vol. 149, art. ID. 103842, D0I:10.1016/j.mechmachtheory.2020.103842.

[59] Litvin, F.L., Feng, P.H., Lagutin, S.A. (2000). Computerised generation and simulation of meshing and contact analysis of new type of Novikov-Wildhaber helical gears. NASA ARLCR-428.

[60] Litvin, F.L., Lu, J. (1993). Computerised simulation of generation, meshing and contact of double circular-arc helical gears. Mathematical and Computer Modelling, vol. 18, no. 5, p. 31-47, DOI:10.1016/0895-7177(93)90131-H.

[61] Yang, S.-C. (2009). Mathematical model of a stepped triple circular-arc gear. Mechanism and Machine Theory, vol. 44, no. 5, p. 1019-1031, D0l:10.1016/j. mechmachtheory.2008.05.013.

[62] Ariga, Y., Nagata, S. (1985). Load capacity of a new W-N gear with a basic rack of combined circular and involute profile. Journal of Mechanical Design, vol. 107, no. 4, p. 565-572, DOl:10.1115/1.3260764.

[63] Hlebanja, G., Hlebanja, J. (2009). Uniform power transmission gears. Strojniški vestnik - Journal of Mechanical Engineering, vol. 55, no. 7-8, p. 472-483.

[64] Liang, D., Chen, B., Tan, R., Liao, R. (2015). Geometric design and analysis of gear transmission with double circular arc-involute tooth. Proceedings of the Institution of Mechanical Engineers, Part C: Journal of Mechanical Engineering Science, vol. 231, no. 11, p. 2100-2109, DOl:10.1177/0954406215625678.

[65] Chen, Z., Ding, H., Li, B., Lou, L., Zhang, L., Yang, Y. (2017). Geometry and parameter design of novel circular arc helical gears for parallel-axis transmission. Advances in Mechanical Engineering, vol. 9, no. 2 p. 1-11, DOI:10.1177/1687814017690957.

[66] Chen, Z., Zeng, M., Fuentes-Aznar A. (2020). Geometric design, meshing simulation and stress analysis of pure rolling rack and pinion mechanisms. Journal of Mechanical Design, vol. 142, no. 3, art. ID 031122, D0I:10.1115/1.4044954.

[67] Chen, Z., Zeng, M., Fuentes-Aznar, A. (2020). Geometric design, meshing simulation and stress analysis of pure rolling cylindrical helical gear drives. Proceedings of the Institution of Mechanical Engineers, Part C: Journal of Mechanical Engineering Science, vol. 234, no. 15 p. 3102-3115, DOI:10.1177/0954406220912265.

[68] Berlinger, B.E., Coulbourne, J.R. (2012). Convoloid gearing technology. Gear Solutions, p. 50-57.

[69] Hlebanja, J. (1976). Konkav-konvexe Verzahnung: Ermitlung der Zahnflanken und einige Grenzfälle. Antriebstechnik, vol. 15 , no. 6, p. 324-329.

[70] Hlebanja, J., Hlebanja, G., Umberger, M. (2020). S-gear design rules. Ventil, vol. 26 , no. 4, p. 254-263.

[71] Hlebanja, J. (1979). Betriebserfahrung an Kammwalzgetrieben mit Sonderverzahnungen. VDI-Berichte, 332, p. 283-288.

[72] Hlebanja, J., Hlebanja, G. (2010). Spur gears with a curved path of contact for small gearing dimensions. VDI-Berichte, 2108, p. 1281-1294.

[73] DIN 3962-1:1978-08 (1978). Tolerances for Cylindrical Gear Teeth; Tolerances for Deviations of Individual Parameters. Deutsches Institut für Normung, Berlin.
[74] ISO 14635:2006. Gears - FZG test procedures - part 1: FZG test metod A/8,3/90 for relative scuffing load-carryng capacity of oils. International Organization for Standardization, Geneva.

[75] Hlebanja, J., Okorn, I. (1996). Investigation of tooth surfacedurability of non-involute spur gears. VDI-Berichte, 1230, p. 443-450.

[76] Hlebanja, G., Hlebanja, J., Okorn, I. (2000). Research of gears with progressive path of contact. Proceedings of DETC'00; International Power Transmission and Gearing Conference, DETC2000/PTG-14384, p. 1-7, D0l:10.1115/detc2000/ptg14384.

[77] Hlebanja, J., Hlebanja, G. (2005). Anwendbarkeit der S-Verzahnung im Getriebebau. Antriebstechnick, vol. 44, p. 34-38.

[78] Hlebanja, J., Hlebanja, G. (2005). Tooth flank durability of internal S-gears. VDI-Berichte, 1904, p. 385-393.

[79] Hlebanja, G., Hlebanja, J. (2013). Influence of axis distance variation on rotation transmission in S-gears. Proceedings of the International Conference on Gears, p. 669-679.

[80] Kulovec, S., Duhovnik, J. (2013). Variation of S-gear shape and the influence of the main parameters. VDI-Berichte, 2199, p. 1535-1541.

[81] Hlebanja, G., Hlebanja, J., Čarman, M. (2009). Cylindrical wormgearings with progressively curved shape of teeth flanks. Strojniški vestnik - Journal of Mechanical Engineering, vol. 55, no. 1, p. 5-14.

[82] Duhovnik, J., Zorko, D., Sedej, L. (2016). The effect of the teeth profile shape on polymer gear pair properties. Technical Gazette, vol. 23, no. 1, p. 199-207, D0l:10.17559/TV20151028072528.

[83] Zorko, D., Kulovec, S., Tavčar, J., Duhovnik, J. (2017). Different teeth profile shapes of polymer gears and comparision of their performances. Journal of Advanced Mechanical Design, System and Manufacturing, vol. 11, no. 6, p. 1-10. DOI:10.1299/jamdsm.2017jamdsm0083.

[84] Hlebanja, G., Kulovec, S., Zorko, D., Hlebanja, J., Duhovnik, J. (2017). Influence of the tooth flank shape on thermal load of the gear. Proceedings of the International Conference on High Performance Plastic Gears, p. 1583-1592, DOI:10.51202/9783181022948-1583.

[85] Trobentar, B., Kulovec, S., Hlebanja, G., Glodež, S. (2020). Experimental failure analysis of S-polimer gears. Engineering Failure Analysis, vol. 111, no. 4, art. ID 104496. DOI:10.1016/j.engfailanal.2020.104496.

[86] Hlebanja, G., Kulovec, S. (2018). Thermal properties of S-gears in comparison with involute gears. IOP Conference Series: Materials Science and Engineering, vol. 393, art. ID. 012067, D0l:10.1088/1757-899X/393/1/012067.

[87] Wadagaonkar, S., Shinde, S. (2015). Cosine gear stress analysis with experimental validation and comparison with involute gear. International Journal of Innovative Science, Engineering \& Technology, vol. 2, no. 3, p. 438-443.

[88] Liu, L., Meng, F., Ni, J. (2019). A novel non-involute gear designed based on control of relative curvature. Mechanism and Machine Theory, vol. 140, p. 144-158, D0l:10.1016/j. mechmachtheory.2019.05.022. 